Service social

\title{
Commentaire sur la communication de Paul Taylor
}

\section{Bernadette Ngo-Nkouth}

Volume 46, numéro 2-3, 1997

Groupes - Symposium 1997

URI : https://id.erudit.org/iderudit/706757ar

DOI : https://doi.org/10.7202/706757ar

Aller au sommaire du numéro

Éditeur(s)

École de service social de l'Université Laval

ISSN

1708-1734 (numérique)

Découvrir la revue

Citer cet article

Ngo-Nkouth, B. (1997). Commentaire sur la communication de Paul Taylor.

Service social, 46(2-3), 33-35. https://doi.org/10.7202/706757ar d'utilisation que vous pouvez consulter en ligne.

https://apropos.erudit.org/fr/usagers/politique-dutilisation/ 


\section{Commentaire sur la communication Vers un développement international du travail social de groupe L'établissement des échanges frontaliers culturels et linguistiques}

Bernadette NGO NKOUTH

Le thème du développement international du travail social de groupe présente un grand intérêt pour moi, puisque je viens d'une culture différente de celle dans laquelle je suis actuellement une formation. Je viens en effet du Cameroun où j'ai travaillé au ministère des Affaires sociales et de la Condition féminine, et j'y retournerai certainement après ma formation à l'École de service social de l'Université Laval. Je partage en grande partie les idées développées par le professeur Taylor. Qu'il me soit permis, toutefois, de faire brièvement état de deux préoccupations, dont l'une tient de la question de la différence dans la définition des concepts et l'autre de la faisabilité du principe de la réciprocité dans le modèle proposé.

S'agissant de la première préoccupation, le professeur Taylor a mis en relief la différence qui apparaît souvent dans la définition et l'interprétation d'un même concept selon le contexte culturel. Pour lui, cette différence constitue une des limites au développement international du travail social de groupe. Je partage cette opinion et je souhaite abonder dans le même sens en mentionnant que cette préoccupation est encore plus grande pour nous, les travailleurs sociaux camerounais, qui restons encore largement dépendants des théories et des concepts élaborés dans les pays du Nord dans le 
champ du service social. De plus, la plupart des politiques et des projets sociaux bénéficient de financements extérieurs qui véhiculent, par le fait même, des valeurs modernes et des concepts nouveaux. Vous pouvez facilement imaginer la complexité de la tâche qui incombe aux intervenants sociaux camerounais. Ceux-ci doivent non seulement comprendre et maîtriser les différents contenus qu'un même concept peut recouvrir, mais aussi les traduire pour les intégrer dans leur propre contexte national et culturel dans le respect des valeurs et des pratiques locales. Pour illustrer mon propos, j'ai retenu le terme participation pris dans deux cultures organisationnelles des services sociaux, soit celle du Québec et du Cameroun. Au Québec, le terme participation réfère à l'implication des usagers dans l'organisation et la gestion des services sociaux. Dans la réalité camerounaise, la participation renvoie à l'implication de l'usager comme contrepartie à l'aide que l'État lui fournit; ainsi, l'usager doit s'impliquer dans son propre relèvement et sa prise en charge dans la perspective de la réalisation de son autonomie. Voilà un terme français qui se retrouve avec deux interprétations complètement différentes. Devant cette réalité, que proposez-vous pour transcender la question de la différence du contenu des concepts dans le cadre du développement international du travail social de groupe, tout en respectant la différence et l'identité culturelle?

En ce qui concerne ma seconde préoccupation, elle a trait au modèle de construction d'une rencontre culturelle proposé par le professeur Taylor. Comme il vient de le mentionner, ce modèle met en relief l'infrastructure de l'interculturalisme constitué par les trois étapes que sont l'analyse, le transfert et la reconstruction et basé sur le principe de la réciprocité de ce processus. Ce qui suppose que le modèle tient pour acquis que les acteurs des différentes cultures en présence dans une rencontre interculturelle possèdent les compétences communicatives nécessaires pour franchir ces trois étapes. Bien que je sois fascinée par le travail de recherche réalisé par le professeur Taylor pour élaborer ce modèle qui, en théorie, permettrait une analyse et une compréhension " emic " mutuelle des cultures, je reste néanmoins préoccupée par son applicabilité. Ma préoccupation porte sur la réciprocité du mouvement si l'on tient compte de la remarque du professeur Taylor qui a dit tout à l'heure et je cite : "Une rencontre internationale ou interculturelle n'est jamais neutre. » Consciente des enjeux qui sont présents dans une rencontre 
interculturelle, je pose la question : Pensez-vous que cette réciprocité soit réaliste? Est-ce qu'elle se réalise quelque part? Ou alors est-ce une utopie dans la mesure où il existe des cultures dominantes et des cultures dominées?

Pour conclure, je rappelle mes deux préoccupations, à savoir la question de la différence des contenus des concepts, qui constitue une limite dans le développement international du travail social de groupe, et la question de la faisabilité du principe de réciprocité dans une rencontre interculturelle. Si cette communication suscite des préoccupations qui tiennent du texte, elle suscite aussi des réflexions qui vont au-delà du texte. Ainsi, cette communication, qui m'interpelle personnellement, m'amène à m'interroger sur la fonction, le rôle et les pratiques du service social au Cameroun, si l'on considère que le service social est un produit occidental importé par la colonisation. Au moment où le service social occidental s'interroge et où se pose la question du renouvellement des pratiques sociales, n'est-il pas temps pour nous, travailleurs sociaux d'Afrique et spécifiquement du Cameroun, de dépoussiérer les pratiques sociales locales méconnues, de les comprendre et d'identifier les aspects importants qui pourraient enrichir nos pratiques modernes? Ces questions peuvent paraître complexes, mais il est pertinent dans le cadre d'un symposium international sur le travail de groupe d'y réfléchir.

Bernadette NGO NKOUTH

Ministère des Affaires sociales et de la Condition féminine Yaoundé, Cameroun

Étudiante au doctorat en service social École de service social Université Laval 